Feinstein, A.R. \& Di Massa, R. (1959) Prognostic significance of valvular involvement in acute rheumatic fever. New Engl. J. Med. 260, 1001.

FRIEDBERG, C.K. (1959) Rheumatic fever in adults; criteria and implications. Circulation, 19, 161.

JOINT REPORT (1955) Treatment of acute rheumatic fever in children. A co-operative clinical trial of A.C.T.H., cortisone and aspirin, by the Rheumatic Fever Working Party of the M.R.C., Great Britain, and the Sub-committee of Principal Investigators of the American Council on Rheumatic Fever and Congentical Heart Disease, American Heart Association. Brit. med. J. 1, 555.

JoNEs, T.D. (1944) Diagnosis of rheumatic fever. J. Amer. med. Ass. 126, 481.

PADER, E. \& Elster, S.K. (1959) Studies of acute rheumatic fever in adults. I. Clinical and laboratory manifestations in 30 patients. Amer. J. Med. 26, 424.

PRICE, W.H. (1968) The electrocardiogram in males with extra Y chromosomes. Lancet, i, 1106.
Rosenberg, D.H. (1946) Clinical aspects of rheumatic fever in adults. New Engl. J. Med. 234, 148.

Stollermann, G.H., Lewis, A.J., Shultz, L. \& Taranta, A. (1956) Relationship of immune response to Group A streptococci to the course of acute, chronic and recurrent rheumatic fever. Amer. J. Med. 20, 163.

TARAN, L.M. \& SzILyagi, N. (1951) The measurement of the QT interval in acute heart disease. Bull. St. Francis Sanat., Roslyn N.Y., 8, 13; reprinted in TARAN, L.M. (1967) Collected Works on Rheumatic Fever, p. 153. International Professional Publishing Inc., New York.

WeE, A.S.T. \& Goodwin, J.F. (1966) Acute rheumatic fever and carditis in older adults. Lancet, ii, 239.

WiLson, M.G. \& LiM, W.N. (1957) The natural history of rheumatic heart disease in the third, fourth and fifth decades of life. I. Prognosis with special reference to survivorship. Circulation, 16, 700.

Wood, P. (1956) Diseases of the Heart and Circulation, 2nd edn, p. 515. Eyre \& Spottiswoode, London.

\title{
Sarcoma at the site of previous trauma in Paget's disease
}

\author{
J. C. Semple \\ F.R.C.S.E. \\ Nuffield Department of Orthopaedic Surgery, \\ University of Oxford
}

MCKenNA et al. (1964) in their review of osteogenic sarcoma in Paget's disease referred to four cases in the literature in which there was good evidence of previous trauma at the ultimate site of neoplastic change. The following case report describes a similar coincidence.

\section{Case report}

A 61-year-old man attended hospital in 1952 complaining of pain in the left shoulder following a fall a few days previously. No bony injury was found, but the changes of Paget's disease were noted in the left humerus and scapula. His symptoms settled without any specific treatment (Fig. 1).

In 1956 he fell down stairs and suffered a closed fracture of the surgical neck of the left humerus (Fig. 2). This was treated by a plaster of Paris U-slab and sling, and it healed solidly with some overriding (Fig. 3); 3 months later he was back at work as a carpenter. Over the next 10 years he was seen occasionally with backache due to his progressing Paget's disease and was also treated for moderate high-output cardiac failure.

In November 1967 he attended, complaining of increasing pain and swelling of the left shoulder.

On examination he was emaciated, and had a gross dorsal kyphosis, enlargement of the head and bowing of his tibiae. The left shoulder was swollen, red, warm and tender, and had no passive or active range of movement. The radiological appearance of the shoulder was difficult to interpret due to the gross change of Paget's disease, but there was a suspicion of erosion of the lateral cortex of the head of the humerus.

Biopsy of the shoulder was performed and showed the whole region of the deltoid muscle to be invaded by a soft, friable grey tumour. Treatment in this old and weak man was limited to strong analgesia. His condition deteriorated rapidly and he died on 14 December 1967, 1 month after his presentation at hospital.

\section{Necropsy}

The presence of widespread, gross osteitis deformans was confirmed, and the surgical neck of the humerus was found to be fractured at the lower border of the tumour (Fig. 4). The tumour had extended into the superior scapular region, but no remote metastases were found. The parathyroid glands appeared grossly normal, but histologically showed predominance of chief cell types, although occasional oxyntic cells were present, and loss of fat.

Sections of the tumour revealed a markedly anaplastic lesion, with little matrix formation, the best defined of which was cartilaginous. Wide areas 


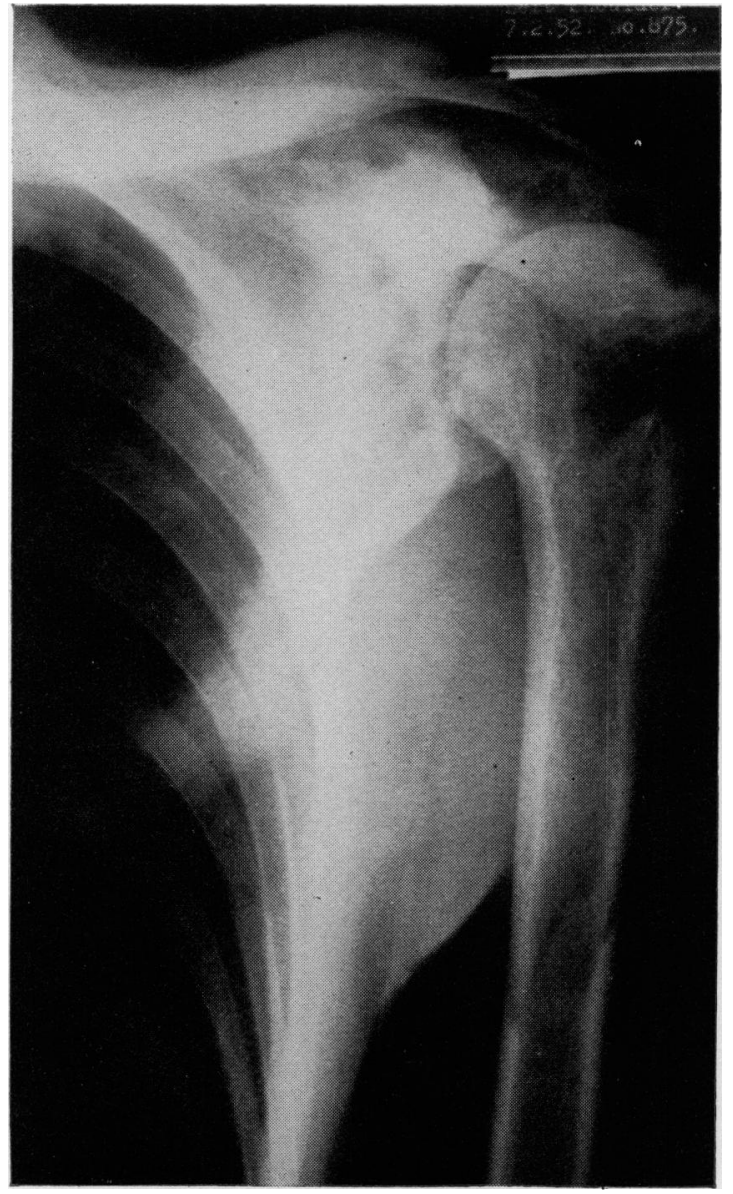

FIG. 1. Radiograph of initial injury in 1952 showing changes of early Paget's disease.

of the tumour were necrotic, and in these areas tumour bone was evident.

\section{Comment}

This case presents a number of classical elements or facets of osteogenic sarcoma arising in Paget's disease of bone, and in particular raises the interesting point regarding the aetiological significance of previous traumatic fracture. This tumour arose in an elderly man, and presented with pain and swelling and inconclusive X-ray appearances. These points are all characteristic of this type of tumour. Treatment of this condition is usually limited to palliative radiotherapy and drugs, as amputation is often impracticable due to the proximal site of the tumour.

The poor prognosis in this condition is illustrated by the fact that McKenna et al. (1964) could find only four proven instances of survival more than

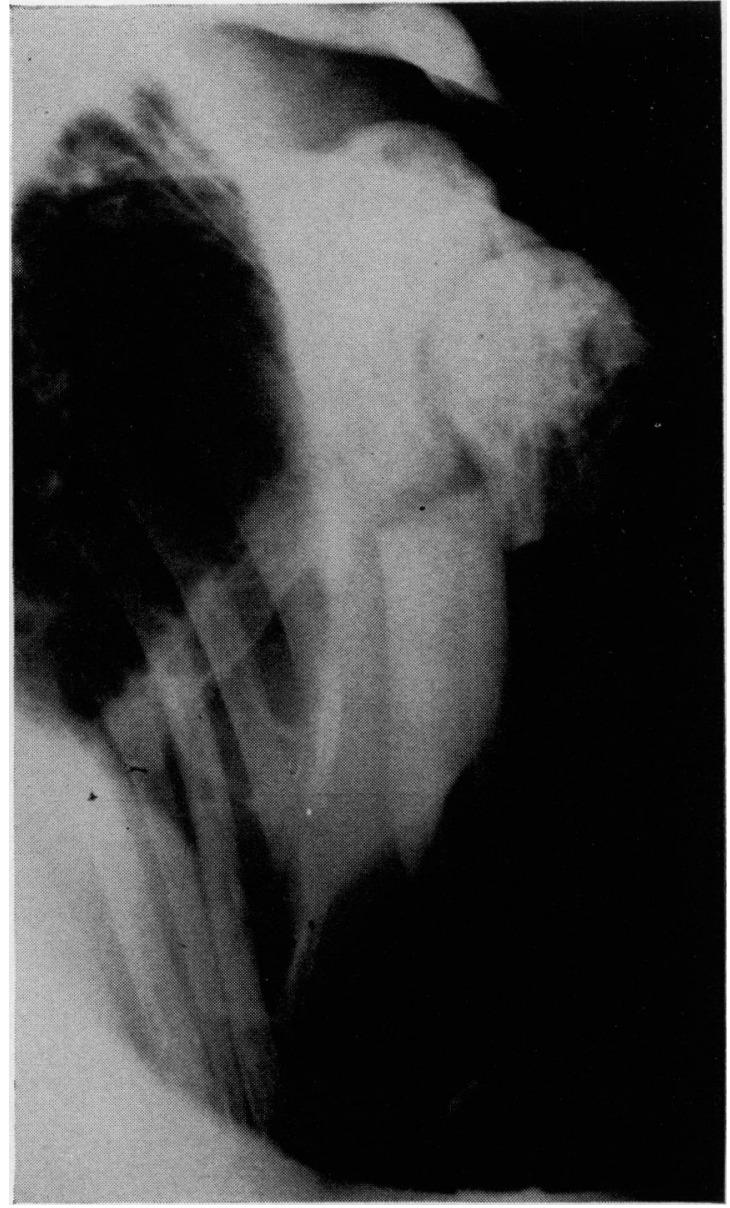

Fig. 2. Radiograph of fractured humerus in December 1956.

5 years after diagnosis in their collected series of 212 cases.

Fracture has been held to be an aetiological factor in the development of sarcoma in the presence of Paget's disease, and this point has been argued in the paper by McKenna et al. (1964) and Poretta, Dahlin \& James (1957). It is important that a distinction be drawn between fractures which occur through a developing sarcoma, and those which are clearly antecedent events with full clinical healing occurring before the development of sarcomatous change.

After a careful search of the literature McKenna et al. (1964) were only able to find four cases in which fractures had clearly antedated the diagnosis of tumour formation, by $1,2,3 \frac{1}{2}$ and 8 years. All these fractures had healed clinically before the subsequent development of malignancy. From their study, McKenna et al. (1964) felt they had no evidence to 


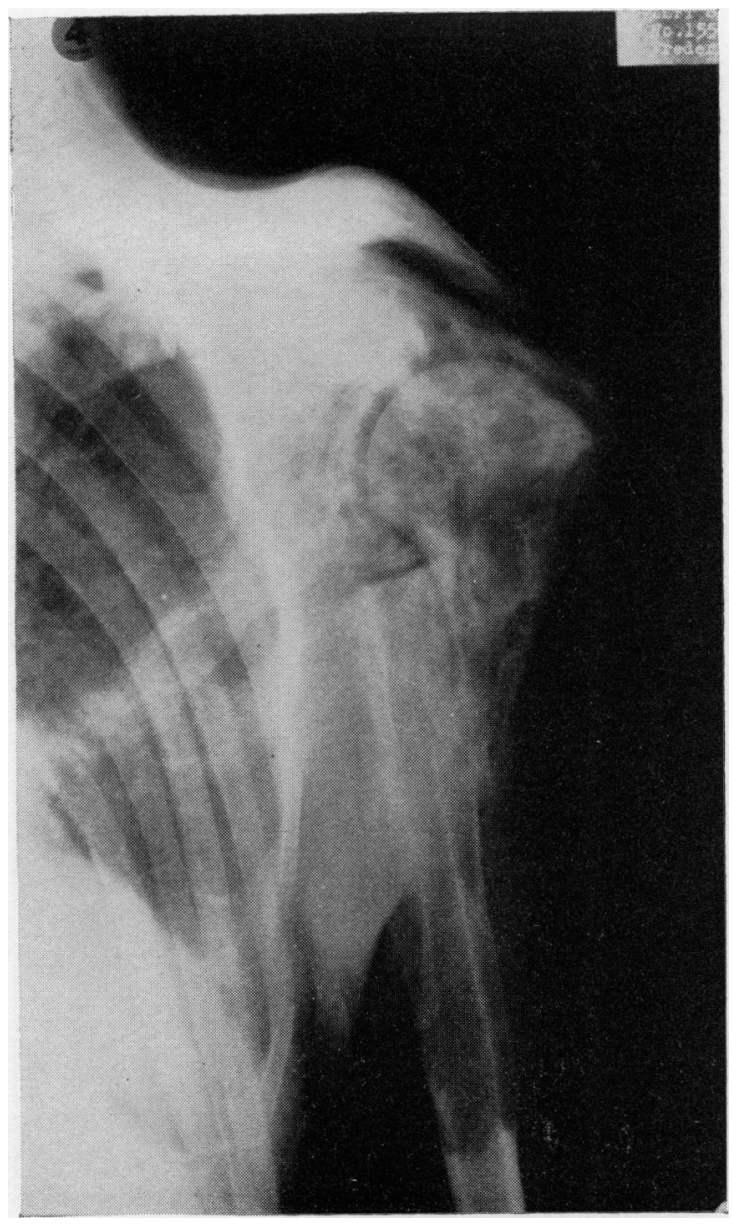

Fig. 3. Radiograph of healed humeral fracture in March 1957.

support the contention that trauma or fracture was an aetiological factor in the production of malignancy in Paget's disease.

Poretta et al. (1957) reviewing a slightly smaller collection than McKenna estimated that $18 \%$ of sarcomata occurring in long bones affected by Paget's disease occurred at the site of previous fracture. The delay between fracture and tumour detection was, however, small, being 6 weeks to 7 months, and it seems likely that at least some of these fractures had occurred through early tumour. Poretta and his colleagues considered that no statistical conclusion regarding pre-existing trauma and development of sarcoma in Paget's disease could be made, but they nevertheless felt that a distinct hazard exists following fracture, or by implication osteotomy, in bone affected by Paget's disease.

It is not considered that this case either supports

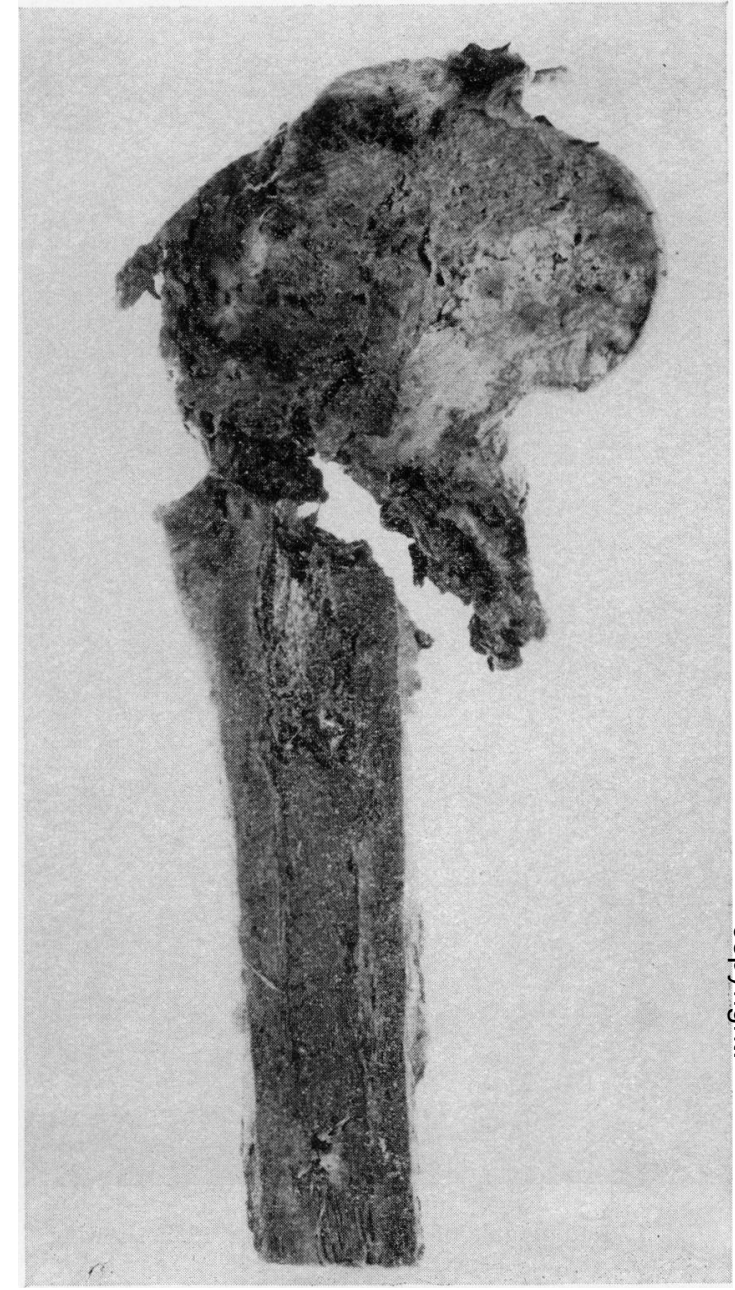

FIG. 4. Photograph of necropsy specimen of tumour involving humerus and scapula, showing pathological fracture of upper end of humerus.

or refutes the relationship of trauma to malignant change in Paget's disease, as they may have occurred quite coincidentally. It is felt, however, that a welldocumented case of trauma followed by proven malignancy in a known case of Paget's disease is worth recording.

\section{Acknowledgment}

I should like to thank Mr J. W. Goodfellow for allowing me to report this case, and for helpful criticism of the manuscript.

\section{References}

McKenna, R.J., Schriviner, C.P., Soong, K.Y. \& HiginBOthaM, N.L. (1964) Osteogenic sarcoma arising in Paget's disease. Cancer, 17, 42.

Porretta, C.A., Dahlin, D.C. \& JAmes, J.M. (1957) Sarcoma in Paget's disease of bone. J. Bone Jt Surg. 39A, 1314. 